\title{
Uso dos resultados do Saresp e formação de professores: a visão dos níveis centrais
}

ADRIANA BAUER*

\section{RESUMO}

Este trabalho tem como objetivo comunicar resultados da pesquisa Uso dos resultados do Saresp: o papel da avaliação nas politicas de formação docente, que realizei durante o mestrado. Ao considerar as declarações dos gestores da educação que implantaram o Sistema de Avaliação de Rendimento Escolar de São Paulo (Saresp) de que este seria também um importante subsídio para a formulação de cursos de desenvolvimento profissional docente, procurei verificar em que medida tal indicador era utilizado como referencial para a definição das necessidades formativas dos professores da rede estadual de São Paulo. Como recorte, defini que pesquisaria os cursos oferecidos para os professores de Ensino Fundamental I, em Língua Portuguesa. Neste texto, busco discutir parte dos resultados obtidos na pesquisa de campo por meio de entrevistas com técnicos da Coordenadoria de Estudos e Normas Pedagógicas (CENP) e da Fundação para o Desenvolvimento da Educação (FDE), bem como com os agentes relacionados à discussão dos resultados da avaliação e com os responsáveis pelas atividades de formaçấo no nível intermediário do sistema, ou seja, nas diretorias de ensino. Tais resultados referem-se ao discurso desses agentes a respeito de como os resultados da avaliação influenciam as propostas de formação docente.

Palavras-chave: Saresp, avaliação da educação, formação de professores, rendimento escolar.

\section{RESUMEN}

Este trabajo tiene como objetivo mostrar resultados de la investigación Uso de los resultados del Saresp: el papel de la evaluación en las politicas de formación docente, que realicé durante la

* Adriana Bauer é Doutoranda do Programa de Educação da Faculdade de Educação da Universidade de São Paulo (dri_bauer@yahoo.com.br). 
maestría. Al considerar las declaraciones de los gestores de la educación que implementaron el Sistema de Evaluación de Rendimiento Escolar de São Paulo (Saresp) de que éste sería también un importante subsidio para la formulación de cursos de desarrollo profesional docente, procuré verificar en qué medida tal indicador era utilizado como referencia para la definición de las necesidades formativas de los profesores de la red estadual de São Paulo. Como recorte, definí que investigaría los cursos ofrecidos para los profesores de Enseńanza Fundamental I, en Lengua Portuguesa. En este texto, intento discutir parte de los resultados obtenidos en la investigación de campo por medio de las entrevistas con técnicos de la Coordenadoria de Estudos e Normas Pedagógicas (CENP) y de la Fundação para o Desenvolvimento da Educação (FDE), como así también con los agentes relacionados a la discusión de los resultados de la evaluación y con los responsables por la actividad de formación en el nivel intermediario del sistema. Dichos resultados se refieren al discurso de esos agentes en cuanto a cómo los resultados de la evaluación influyen en las propuestas de formación docente.

Palabras clave: Saresp, evaluación de la educación, formación de profesores, rendimiento escolar.

\section{ABSTRACT}

The purpose of this article is to present the results of the research: Using Saresp's results: the role of evaluation policies in teacher training, which I conducted during my master's. Upon considering the statements of the education managers who introduced the Evaluation System of Student Performance in the State of São Paulo (Saresp) that this would also be an important subsidy to set up professional teacher enhancement courses, I tried to study to what extent this index was used as a reference to define the training needs of the state teachers in São Paulo. I focused on the courses offered to Elementary I teachers in Portuguese Language. In this article I try to discuss some of the results obtained in the field research through interviews with the technical staff of the Committee for Studies and Pedagogical Norms (CENP) and the Foundation for Educational Development (FDE), as well as with the agents related to the discussion of the evaluation results and those responsible for the training activities in the system's middle level, that is, the teaching boards. These results refer to the agents' discourse concerning how the evaluation results influence proposals for teacher training.

Keywords: Saresp, evaluation of education, teacher training, student performance. 


\section{INTRODUÇÃO}

A pesquisa que originou o presente texto foi realizada em 2006 e tinha como objetivo compreender a relação entre os resultados do Saresp e a elaboração de políticas de formação docente anunciadas em seus documentos oficiais ao longo de sua existência. Sua realização contemplou uma pesquisa de campo, em que foram visitadas algumas diretorias regionais situadas na cidade de Sáo Paulo, com o intuito de apreender a percepção que os assistentes técnico-pedagógicos, supervisores de ensino/coordenadores do Saresp e os próprios dirigentes regionais tinham sobre a possibilidade de usar os resultados da avaliação externa para o diagnóstico de necessidades formativas dos professores, para, então, fazer a proposição de atividades, a fim de saná-las. Também foram entrevistados técnicos da CENP e da FDE, órgãos relacionados à Secretaria da Educação do Estado de São Paulo, com a finalidade de entender a relação que aparecia tecida tão logicamente nos documentos oficiais.

A pesquisa realizada diferiu da que havia sido planejada, em razão da dificuldade em contatar as instituiçóes que seriam visitadas. O campo, que inicialmente abrangeria as treze diretorias da capital, teve de ser reduzido a quatro delas, pois estava difícil conseguir permissão para realizar as entrevistas com os agentes definidos.

Mesmo assim, foram realizadas 14 entrevistas com profissionais de diretorias de ensino, duas com técnicos da educação da FDE e uma na CENP, órgãos escolhidos para representar a fala da Secretaria da Educação, como mostra o quadro 1.

\section{OS INDICADORES DE ANÁLISE}

Os indicadores definidos previamente para embasar a análise do conteúdo das entrevistas foram: condiçôes de acesso aos resultados da avaliação; existência de reunióes gerais para discussão dos resultados da avaliação com os profissionais diretamente envolvidos no trabalho da escola; existência de atividades programadas para discussóes sobre possíveis intervençóes nas escolas realizadas pelos ATP's e Supervisores; planejamento de trabalhos específicos que se relacionem à formaçáo docente; organização, pela equipe da diretoria regional, de cursos e atividades similares para as escolas.

Buscou-se também obter informaçóes referentes ao entendimento dos agentes das diretorias regionais no que se refere ao Saresp e à formaçáo de professores, por meio da análise do discurso dos profissionais da diretoria regional nas várias atividades relacionadas acima; do posicionamento político-pedagógico desses profissionais perante as políticas de avaliaçáo e gestão implantadas no período estudado; a importância que atribuem, em sua fala, à discussáo dos resultados e a disponibilidade que mostram para incorporar os resultados da avaliação à sua prática profissional. 
Quadro 1 - Entrevistas realizadas nas diretorias regionais

\begin{tabular}{|c|c|c|c|c|c|}
\hline \multirow[b]{2}{*}{$\begin{array}{c}\text { DIRETORIA } \\
\text { REGIONAL } \\
\text { (Nome } \\
\text { Fantasia) }\end{array}$} & \multicolumn{5}{|c|}{ PROFISSIONAIS ENTREVISTADOS } \\
\hline & $\begin{array}{c}\text { Supervisor de } \\
\text { Ensino } \\
\text { (Coordenador } \\
\text { da Avaliação) }\end{array}$ & $\begin{array}{c}\text { Assistente } \\
\text { Técnico } \\
\text { Pedagógico } \\
\text { de Língua } \\
\text { Portuguesa } \\
\text { (1 a a 4a séries) }\end{array}$ & $\begin{array}{c}\text { Assistente } \\
\text { Técnico } \\
\text { Pedagógico } \\
\text { de Língua } \\
\text { Portuguesa } \\
\text { (5 a } 8^{\text {a }} \text { séries) } \\
\end{array}$ & $\begin{array}{l}\text { Coordenador } \\
\text { da Oficina } \\
\text { Pedagógica* }\end{array}$ & $\begin{array}{l}\text { Dirigente } \\
\text { Regional de } \\
\text { Ensino }\end{array}$ \\
\hline DE Gama & $\begin{array}{c}\text { Não retornou o } \\
\text { contato }\end{array}$ & $\begin{array}{l}\text { Entrevista } \\
\text { substituída } \\
\text { pela do } \\
\text { Coordenador } \\
\text { da Oficina } \\
\end{array}$ & $\begin{array}{l}\text { Entrevista } \\
\text { substituída } \\
\text { pela do } \\
\text { Coordenador } \\
\text { da Oficina } \\
\end{array}$ & $\mathrm{x}$ & Em férias \\
\hline DE Alpha & $\mathrm{X}$ & $\begin{array}{c}\text { Não se } \\
\text { disponibilizou } \\
\text { a dar } \\
\text { entrevista }\end{array}$ & $X$ & $\begin{array}{l}\text { Não há nesta } \\
\text { diretoria }\end{array}$ & $X$ \\
\hline DE Beta & $\mathrm{X}$ & $\mathrm{X}$ & $x$ & $\begin{array}{l}\text { Não há nesta } \\
\text { diretoria }\end{array}$ & $\mathrm{X}$ \\
\hline DE Delta & $\mathrm{X}$ & $\mathrm{X}$ & $\mathrm{X}$ & É a ATP de LP & $\mathrm{X}$ \\
\hline DE Ômicrom & Em férias & $\begin{array}{c}\text { Entrevista } \\
\text { substituída } \\
\text { pela do } \\
\text { Coordenador } \\
\text { da Oficina }\end{array}$ & $\begin{array}{c}\text { Entrevista } \\
\text { substituída } \\
\text { pela do } \\
\text { Coordenador } \\
\text { da Oficina }\end{array}$ & $\mathrm{X}$ & $x$ \\
\hline
\end{tabular}

* Em duas das diretorias visitadas, havia um responsável pela Oficina Pedagógica (o chamado Coordenador de OP), que responde pelo trabalho realizado nesse departamento. Nesses casos, quando foi solicitada a entrevista com os assistentes técnico-pedagógicos (ATP's), a entrevistadora foi encaminhada para o coordenador, não sendo possível o contato direto com os assistentes, como previsto inicialmente. Vale ressaltar que essa figura de Coordenador de Oficina não está presente em todas as instituições, sendo que em uma delas não havia nem o assistente técnico pedagógico.

A hipótese relacionada a essas observaçóes foi que tal comportamento e posicionamento político poderiam estar influenciando o trabalho realizado no âmbito das DE's, sendo que se considerou importante captar se os usos dos resultados da avaliação na diretoria não seriam dependentes de traços pessoais dos agentes dessas instituiçóes, ou, ainda, de características das equipes que as compóem.

Uma das dificuldades encontradas na análise dos dados obtidos foi o desencontro, e até mesmo a contradição, entre informações colhidas dentro de uma mesma diretoria a respeito de um mesmo indicador.

Essas incongruências permitem inferir que há um vácuo na comunicação interna, contradizendo a fala de algumas equipes que afirmam a realizaçáo de um trabalho em conjunto. Também levam à suspeita de que nem sempre o que é declarado corresponde ao que é realizado, o que explicaria o surgimento de depoimentos diversos sobre um mesmo aspecto. Algumas contradiçôes podem ser destacadas até no discurso de um mesmo profissional. 
Mesmo considerando a distância entre o discurso e a realidade, é necessário admitir que, contrariando as hipóteses iniciais da pesquisadora, muitas açóes vinham sendo realizadas tendo como base os resultados da avaliação. Talvez a utilização dos resultados observada náo foi aquela declarada nos documentos oficiais, mas parece ser possível afirmar que as diretorias realizavam açóes baseando-se nos dados obtidos. Pode-se questionar a efetividade e importância dessas açóes, no que se refere à contribuição para a melhoria da qualidade do ensino que era o objetivo final da política educacional do Estado. Mas esse questionamento não foi objeto da investigação, demandando estudos de outra natureza que pudessem contribuir para essa reflexão.

Quanto ao uso dos resultados da avaliação para o planejamento de açóes específicas de formação, foco deste trabalho, mesmo nas diretorias em que estes resultados pareciam ser pouco considerados, o discurso das equipes quase sempre reforçou a importância da avaliação para o redimensionamento e planejamento do trabalho. Inúmeros usos dos resultados, mais gerais, foram salientados, principalmente no que se refere à adaptação do currículo e da metodologia de ensino adotada.

Notou-se, também, que, apesar de o discurso de alguns supervisores e assistentes técnico-pedagógicos salientar a importância de diagnosticar o sistema de ensino por via da avaliação, os depoimentos permitiram inferir que as possibilidades de análise e proposição de açóes com base no diagnóstico ainda estavam sendo construídas, em parte em virtude da dificuldade das equipes escolares e das diretorias se apropriarem dos dados, interpretando-os e ressignificando-os.

O fato permitiu questionar em que medida as diretorias de ensino e as escolas criaram rotinas que incorporam os dados obtidos por meio da prática da avaliaçáo. A fim de responder a esse questionamento, os indicadores previamente definidos foram agrupados em categorias de análise para serem explorados mais detidamente.

1) Acesso dos profissionais da diretoria regional aos resultados da avaliação e discussão dos resultados.

2) Sistematização das análises dos resultados e proposição de ações (relatórios, planos de trabalho).

3) Existência de atividades de formação (na Secretaria, nas diretorias, nas escolas).

4) Outros usos dos resultados e mecanismos de indução/controle desses usos.

O quadro 2 sistematiza os dados obtidos na pesquisa de campo, a partir dos indicadores de uso dos resultados previamente definidos, exemplificando a diversidade de açóes existentes entre as diretorias visitadas e os seus diferentes graus de 
envolvimento nas ações articuladas pela Secretaria da Educação e na mobilização das equipes para a realização de atividades de formação docente e reunióes para o tratamento dos dados do Saresp.

Quadro 2 - Sistematização das informações obtidas na pesquisa de campo

\begin{tabular}{|c|c|c|c|c|c|}
\hline \multirow{2}{*}{$\begin{array}{l}\text { DIRETORIA REGIONAL } \\
\text { (Nome Fantasia) }\end{array}$} & \multicolumn{5}{|c|}{$\begin{array}{l}\text { USOS DOS RESULTADOS DO SARESP NO ÂMBITO DA DIRETORIA } \\
\text { REGIONAL: INDICADORES }\end{array}$} \\
\hline & DE Alpha & DE Beta & DE Gama & DE Delta & DE Ômicrom \\
\hline $\begin{array}{l}\text { Acesso declarado pelos } \\
\text { profissionais da DE aos resultados } \\
\text { da avaliação }\end{array}$ & & & $x$ & & $x$ \\
\hline $\begin{array}{l}\text { Atividades programadas entre } \\
\text { supervisores e ATP's para discussão } \\
\text { sobre intervenções nas escolas }\end{array}$ & & $x$ & $x$ & & $x$ \\
\hline $\begin{array}{l}\text { Reuniões entre escolas e DE para } \\
\text { troca de experiências /capacitações } \\
\text { conjuntas }\end{array}$ & & $x$ & $x$ & & \\
\hline $\begin{array}{l}\text { Relatórios anuais com análise de } \\
\text { resultados } \\
\text { (oficina/supervisor) }\end{array}$ & & & $x$ & & \\
\hline $\begin{array}{l}\text { Reuniões de preparo para a } \\
\text { avaliação }\end{array}$ & $x$ & $x$ & $\mathrm{x}$ & & $x$ \\
\hline $\begin{array}{l}\text { Reuniões de divulgação dos } \\
\text { resultados }\end{array}$ & $x$ & $\mathrm{x}$ & $x$ & & $x$ \\
\hline $\begin{array}{l}\text { Reuniões de acompanhamento } \\
\text { durante o ano }\end{array}$ & & $x$ & $x$ & $x$ & \\
\hline $\begin{array}{l}\text { Participação da equipe de ATP/ } \\
\text { supervisão nas HTPC's }\end{array}$ & $x$ & & $x$ & & \\
\hline $\begin{array}{l}\text { Atividades de formação de } \\
\text { professores, CP e diretor, } \\
\text { vinculadas aos resultados do } \\
\text { Saresp, na própria diretoria }\end{array}$ & & $x$ & $x$ & & \\
\hline $\begin{array}{l}\text { Organização de cursos/palestras } \\
\text { com técnicos de fora da DE }\end{array}$ & & & & $x$ & \\
\hline $\begin{array}{l}\text { Sistemática de cobrança na escola } \\
\text { do uso dos resultados (elaboração } \\
\text { de relatórios, projetos de trabalho) }\end{array}$ & $X$ & & $x$ & & \\
\hline
\end{tabular}

Os limites de tempo e espaço para a produção deste artigo farão com que a análise se limite ao primeiro indicador estudado: $o$ acesso aos dados e sua interpretaçáo pelos profissionais envolvidos nas atividades de formação.

\section{A PROBLEMÁTICA DO ACESSO E ENTENDIMENTO DOS DADOS}

Pressupondo que o acesso dos profissionais da diretoria regional e seu entendimento sobre os dados produzidos pelo Saresp influenciavam as propostas de traba- 
lho da instituição, em um primeiro momento os questionamentos realizados durante as entrevistas permitiram compreender como os dados da avaliação chegam às DEs, como eram interpretados e analisados.

Por meio dos depoimentos foi possível traçar, em certo sentido, um histórico sobre como esses dados vinham sendo trabalhados e para que serviram, tanto na escola quanto nas diretorias de ensino, durante os dez anos do Saresp.

Ainda na gestão da Prof ${ }^{a}$ Rose Neubauer, os dados das escolas, organizados em um documento, com estrutura previamente definida, eram enviados às diretorias regionais para serem analisados pelas equipes de avaliação. Com base nesta análise, as equipes das diretorias produziam relatórios ${ }^{1}$ nos quais procuravam compreender os resultados obtidos, relacionando-os às características das regiôes, e estabelecendo metas e diretrizes de trabalho a fim de melhorar os resultados da avaliaçáo.

Segundo uma das técnicas da FDE entrevistada ${ }^{2}$, esse primeiro momento tinha um caráter formativo, pois era necessário capacitar o pessoal da rede, tanto nas diretorias de ensino quanto nas escolas, para compreender os dados e poder ressignificálos em sua prática cotidiana.

As diretorias regionais pareciam ter um trabalho bastante aprofundado de análise, incluindo a crítica ao instrumento de avaliação, como pode ser visto em excerto do Relatório da Diretoria Alpha, do ano 2000: "os conteúdos das questóes estáo adequadas aos PCN's, porém várias questôes não estão de acordo com a realidade em que está inserido o aluno" (Relatório da DE Alpha).

${ }^{1}$ Em sua tese de doutorado, Cristiane Machado (2003) analisou 88 relatórios produzidos pelas diretorias regionais de ensino. Ela explica a sistemática de construção desses relatórios: "Os relatórios de avaliação do processo de aplicação do SARESP das Diretorias de Ensino são baseados nas informações contidas nos relatórios de avaliação que cada escola elabora ao final da aferição. É a partir dessas informações que a equipe de supervisores, que acompanha a aplicação do SARESP, faz análises sobre os avanços e as dificuldades do trabalho pedagógico e as propostas e ações a serem desenvolvidas pelas Diretorias. É importante informarmos como se dá o processo de totalização das notas das escolas pelas Diretorias. Após a correção das provas e a digitaçáo dos dados no programa de informática pelas escolas, as Diretorias importam esses dados para o programa de informática da Diretoria e calculam a média entre as suas escolas" (Machado, 2003, p. 134).

${ }^{2}$ As falas dos entrevistados, quando gravadas, foram transcritas ipsis literis como foram emitidas. Apesar da linguagem usada durante a entrevista ser coloquial, optou-se por mantê-la no trabalho, para que o leitor possa interpretar as omissóes, intervalos, ditos e não ditos que, do ponto de vista da pesquisadora, constituem material interessante que poderá ser utilizado em outras reflexôes. 
Esta etapa, de construção coletiva de relatórios, parece ter significado, para algumas equipes nas diretorias, uma possibilidade de estudo de sua realidade, pois em várias das instituiçóes visitadas os entrevistados insistiram em mostrar esse material: "Nós levamos a sério o estudo, ele nos ajudou... Veja, até parece uma tese" (Depoimento da coordenadora de avaliação da DE Beta); "Eu ainda náo coordenava a avaliação naquela época, mas eles faziam o relatório e era bem complexo" (Anotações do diário de visitas da pesquisadora).

Tal possibilidade variou de diretoria para diretoria, e durante a pesquisa, ao entrar em contato com alguns desses relatórios, foi possível perceber a existência de produçóes pouco profundas, com análises ligeiras, que pouco devem ter contribuído para a formação da equipe ou para o trabalho realizado no âmbito da diretoria.

Foram encontrados, ainda, relatórios compostos, quase que exclusivamente, por tabelas, que as equipes da diretoria produziram com base na análise dos dados, nos quais as reflexóes e proposiçóes parecem ter sido consideradas de somenos importância.

Independentemente da efetividade formativa da produção realizada nesse primeiro momento do trabalho, a partir dos dados da avaliação (relatório), nota-se que a ele seguiu-se uma orientação em que a realização desses relatórios deixou de ser demandada. Também se observa, por meio dos depoimentos, que a Secretaria parece ter modificado suas intençóes no que se refere ao trabalho com resultados, visto que passou a enviar às diretorias os dados estatísticos:

Bom, agora nós recebemos os índices, em porcentagem... Esses índices e as porcentagens também a escola recebe, mas nós fazemos a reuniáo aqui com os diretores das escolas, com os professores-coordenadores pedagógicos e apresentamos todos os dados [...] Ela [a SEE] manda os dados estatísticos e um relatório... O de 2004 [relatório], disse que ia mandar, mas até agora não mandou. (Depoimento do coordenador de Avaliaçáo da DE Alpha)

Olha, realmente, os dados colocados são apenas os dados quantitativos. Nota e porcentagem, por turma... Cada escola recebe de suas turmas. Náo tem uma análise. Mesmo porque não deu tempo deles fazerem. Eles fazem e demoram a enviar, porque submetem a um especialista, é um trabalho sério. (Depoimento do coordenador de avaliação da DE Beta)

Além do envio dos dados em porcentagem, enfatizando o trabalho sobre índices quantitativos, as falas destacam um problema: o tempo que esses dados demoram a chegar na diretoria. 
Na verdade é engraçado que apesar de ter mudado a época da prova ${ }^{3}$, o resultado sempre chegava um pouco defasado. Eu acho que a prova deveria ser um pouco antes, em setembro, para os resultados chegarem em dezembro. Porque aí dá para você ter um tempo hábil para trabalhar. Porque é o seguinte: a escola, em dezembro, já se reúne para fazer a avaliação dela. Então eu acho que deveria ser neste meio... Acho que em novembro fica muito tarde [a realização da prova]. A gente tenta trabalhar através da HTPC, mas eu acho que ainda falta alguma coisa para amarrar melhor, náo sei, precisava discutir. (Depoimento da dirigente da DE Alpha)

Como a diretoria deveria apoiar as análises e o trabalho da escola, soa estranho que esses dados demorem tanto para chegar ao nível intermediário, tendo em vista o caráter de apoio ao trabalho escolar relegado às diretorias, reforçado pela fala da técnica da CENP:

E a orientação é para que as diretorias de ensino e suas equipes acompanhem também o trabalho das escolas. Normalmente como o resultado sai no final do ano, a gente reforça esta orientaçáo no início do ano, no período de planejamento, para que se retome, para que se pegue, lógico que não exclusivamente o Saresp, pois a escola tem o sistema de avaliação dela, interno, também; mas que ela some, agregue a isso também o resultado do Saresp, o questionário do perfil dos alunos, para que ela possa estar, em um momento de planejamento, estar fazendo uma avaliação do seu trabalho, do seu projeto pedagógico, e estar tomando algumas decisóes do ponto de vista do replanejamento para o ano seguinte, fortalecendo o que está dando certo, retomar e rever aquilo que precisa de mudanças. (Depoimento da Representante da Equipe Técnica da CENP, grifos meus)

${ }^{3}$ A coordenadora de avaliação refere-se ao fato de que a partir de 2002 houve uma alteração no momento de realização da prova: até 2000 era feita no início do ano e em 2002 passou a ser feita no final do ano. Uma das técnicas da FDE explicou que quando a prova era realizada no início do ano (avaliação de entrada), os conteúdos avaliados eram os que haviam sido trabalhados na série anterior. Ao mudar a prova para o final do ano, a SEE avalia os conteúdos trabalhados durante o ano, pois os resultados devem embasar o planejamento da série seguinte à avaliada. Exemplo: os resultados da avaliação de 2004, de uma determinada terceira série, devem ser utilizados como parâmetros para o planejamento do trabalho realizado com a quarta série em 2005. 
Considerando que a CENP ressalta a importância das escolas utilizarem os dados do Saresp em seu planejamento de trabalho, devendo ser apoiadas, para isso, pelas diretorias, causou surpresa o conhecimento de que alguns dados vão direto para as escolas, sem passar pelas diretorias, que tentam criar mecanismos para "conhecer" esses dados, mesmo que indiretamente:

[...] quando for o ano que vem que eles já colocam o resultado por habilidade lá no site. A gente tenta, mas ele não vem para a diretoria, vai direto para a escola. Para você ter acesso ao resultado, tem que pedir para a escola te dar os relatórios dela, trazê-los para a diretoria. E é aquela dificuldade, porque é individual. Eu pedi e a I. conseguiu o resultado de $1^{\mathrm{a}}$ a $4^{\mathrm{a}}$ séries. Quando consegui da primeira parte de quinta a oitava, foi quase um mês depois. E só consegui por malandragem: as escolas esqueceram a senha. (Depoimento da ATP de Língua Portuguesa do Ciclo 2, DE Beta, grifos meus)

Como explica uma das supervisoras de ensino, responsável pela Coordenação da Avaliação na Diretoria Delta, apesar de não receberem mais um relatório que apóie o trabalho a ser realizado, seria possível a equipe fazer análises com base nos dados quantitativos. Mas no momento em que a Secretaria decide não enviar mais os dados de cada escola para a diretoria, parece que é criado um descompasso: a diretoria de ensino tem a responsabilidade de acompanhar o trabalho de análise de dados, de auxiliar as escolas na definição dos melhores encaminhamentos, mas ela mesma tem dificuldade de acesso a esses dados, o que pode gerar uma dissociação entre o trabalho das escolas e da diretoria, como de fato aconteceu na maioria das diretorias visitadas.

Por meio de vários depoimentos, nota-se a dificuldade que o não recebimento dos dados do Saresp causa ao trabalho dos técnicos da diretoria. Com exceção de uma Assistente Técnico-pedagógica (ATP), que afirma não precisar deles para acompanhar suas escolas, a maioria dos coordenadores de avaliação e ATP's apontou essa mudança introduzida pela Secretaria como algo negativo e prejudicial ao seu trabalho.

Atualmente, sabemos através das escolas, não recebemos os dados na diretoria [...] Não, são dados numéricos, mas dá para fazer [a análise] porque já sai assim: quantos, naquela tal habilidade (porque eles fazem a avaliação pelas habilidades) e aí sai a porcentagem... Já sai por aluno. Vem assim... Eles [CENP/FDE], um relatório deles, não [recebemos]. Mas a questão numérica sim [...] Antes vinha por escola e por diretoria... Vinha um "resuminho" final... Então, nesta diretoria, 
vinha tanto de aprovação, tanto de reprovação, tantos atingiram a média, tantos não atingiram... E, depois, tinha por escolas [...] Olhava e sabia os resultados dela [...] Esse ano veio um relatório muito bom, para trabalhar [para as escolas]. Veio por aluno e as habilidades; se eles atingiram ou não atingiram. Mas para a supervisáo ficou meio difícil, porque, primeiro, se você quer entrar no banco de dados, separado, você tem que pedir a senha da escola. Eu, como coordenadora, recebi a senha de todas as escolas, mas evidentemente passei para as escolas, porque não ficou comigo e porque eu não vou entrar em uma coisa que não cabe, né? Fica chato, você acaba invadindo um espaço, não é? Entáo para o supervisor é interessante vir um relatório geral, onde você olha, já vê, e aí dá para trabalhar. (Depoimento da Coordenadora de Avaliação da DE Delta, grifos meus)

Para agravar as condiçóes sobre como os dados chegam à diretoria e o tempo que isso leva, pode-se observar nos depoimentos dos supervisores de ensino certa dificuldade para o seu entendimento e utilização.

Todo projeto é desenhado em cima de uma teoria, que é a Teoria da Resposta ao Item [...] Que eu não conheço... Mas está escrito aqui que essa teoria é construída em cima de uma progressão da aprendizagem e que então os alunos de $1^{\mathrm{a}}$ e $2^{\mathrm{a}}$ séries são testados com a mesma prova, bem diversificada. E dessa forma eles vão fazendo níveis de desenvolvimento, por exemplo [...] Toda aquela análise, que é uma coisa complicadíssima, não sei como fazem aquilo [...] Eu acho que isso falta [oferta de atividades de formaçáo para o entendimento e trabalho com os dados]. Por que eles têm uma imensidade de dados e a gente náo sabe usar. Agora veio um CD-Rom com todos esses dados, por escola, por nível, etc. Mas eu acho que é um pouco descolado da produção do aluno, porque a escola é centrada na produção do aluno (e nós também). Entáo essa história de classificar se é melhor, se é pior, para nós é um pouco complicado. Que nível é esse, maior que esse, sabe, classificar esses níveis não tem a ver muito com o dia-a-dia da escola, é complicado. Entáo o disquete está aí e ninguém sabe o que faz. Em termos de diretoria, acho que a gente até poderia aproveitar alguma coisa, mas eu acho que a gente náo tem muito... Agora querem fazer um trabalho com a gente em cima desses dados, para ver como é que a gente, na diretoria de ensino, pode vir a usar. (Depoimento de Supervisora de Ensino, Coordenadora de Avaliação da DE Beta, grifos meus) 
Ainda que alguns profissionais destaquem a dificuldade em entender esses dados, o movimento dos dirigentes regionais é o de afirmar que há um grande apoio da Secretaria à formação dos supervisores e assistentes técnico-pedagógicos para realizar essas análises:

Veja bem, na realidade, eles [SEE] não vão esmiuçar tremendamente. Porque eles vão passar os dados para nós, para as pessoas que estâo sendo capacitadas para a aplicação das provas, para a discussão das provas, para correção das provas e para a utilização das provas no cotidiano, isso nós temos as videoconferências, nós temos encontros presenciais, FDE, uma porção de coisas. (Depoimento da Dirigente Regional da DE Beta, grifos meus)

Nas falas acima, nota-se que, apesar da Coordenadora de Avaliação (que é responsável em planejar, juntamente com a equipe dos ATP's, as análises dos resultados e propor açóes que objetivem a melhoria dos mesmos) confessar sua dificuldade em compreender a sistemática da avaliação e os dados obtidos, e alegar que sente falta de atividades que a preparem para entender melhor esses resultados, sua dirigente regional afirma que a capacitação para o trabalho com os dados é realizada, não parecendo considerar as dificuldades de sua própria equipe.

Mesmo que o discurso de alguns dirigentes entrevistados seja de que a Secretaria auxilia os profissionais da diretoria para o trabalho com os dados, oferecendo capacitaçôes, organizando reuniôes com a comunidade acadêmica e com os técnicos das instituições responsáveis pela avaliação, observa-se uma contradição entre esse discurso e os depoimentos dos supervisores e ATP's. Estes profissionais dizem não receber apoio para o trabalho que devem realizar e apontam a inexistência de materiais específicos que possam ser utilizados para auxiliá-los na compreensáo dos dados da avaliação, bem como sugerir estratégias de ação com base nesses dados.

A mesma "ilusão" de que os técnicos das diretorias regionais estáo bem preparados para o entendimento dos dados e da lógica da avaliação perpassa os discursos das técnicas da CENP e da FDE:

[...] quando ele [Saresp] vai ser aplicado, existem momentos de capacitaçáo para, por exemplo, discutir os critérios de correção das redaçóes. Depois as DE's fazem isso também com suas escolas, com seus professores, porque o fato de você estar envolvendo, ainda que seja na avaliaçáo, de você estar trabalhando desse jeito, você também já está formando e atuando na capacitação continuada desses professores, dentro daqueles critérios ali estabelecidos. (Depoimento da Representante da Equipe Técnica da FDE, grifos meus) 
Informou, ainda, que foi realizado um exaustivo trabalho de capacitaçáo nas diretorias regionais para o trabalho a partir dos dados. Os relatórios das diretorias faziam parte desse trabalho e constituíram uma forma de fazer com que os dados fossem estudados e dessem suporte para a realização do trabalho pedagógico nas escolas e diretorias. Segundo a entrevistada, a idéia seria fazer com que o trabalho a ser realizado a partir dos dados do Saresp fosse incorporado no Plano Diretor da Diretoria Regional, que tem uma equipe para cuidar da avaliação [Saresp], coordenada por um dos supervisores da instituição. (Anotaçôes do diário da pesquisadora em entrevista com a técnica da FDE)

Não se trata de negar, aqui, a existência de um trabalho de apoio aos técnicos da diretoria de ensino sobre como entender e trabalhar com os dados do Saresp. Contrariando as expectativas iniciais da pesquisadora, esse trabalho foi, e ainda é, realizado por meio de palestras e videoconferências.

Em contraposição ao discurso dos profissionais da diretoria, a segunda técnica da FDE, quando entrevistada, apresentou materiais produzidos especificamente para auxiliar no trabalho das escolas e das diretorias. Tais materiais, denominados Orientaçóes para a Interpretação dos Resultados são produzidos em forma de boletim, para três destinatários distintos: a Coordenadoria de Ensino, as diretorias regionais e as escolas.

Este trabalho parece não ser suficiente para preparar os profissionais das diretorias para compreender e analisar os resultados, o que pode resultar em prejuízo à efetividade de seu uso, não somente no nível regional, mas também nas escolas, uma vez que a Secretaria delega à diretoria o suporte às atividades de leitura e interpretação de dados, considerado imprescindível para a realização do trabalho pedagógico, como é apontado a seguir:

Mas também tem uma questão que é a proposta de trabalho da SEE. Eles acreditam que a escola vai fazer um trabalho a partir dos resultados. Eu, a partir da experiência na diretoria de ensino, náo acho que eles consigam, justamente por causa da linguagem que é usada. Vem com uma linguagem que... Teoria de Resposta ao Item... Poxa, se para nós é difícil, imagina na escola. E também tem a linguagem das competências, onde os objetivos vêm em forma de competências. Entáo para eles, na escola, é complicado fazer esse trabalho. De primeira a quarta série, então, nem pensar, não tem condição. Acho que serve para os projetos da Secretaria de Ensino, e para as diretorias de ensino, para poder fazer um trabalho. Eu acho que as diretorias de ensino deveriam ser 
uma das primeiras instâncias capacitadas, trabalhadas, para que se fizesse a capacitação dentro das escolas. Isso que eu acho que é uma falha muito grande. Esse ano nós fomos os últimos a receber os resultados [...] Não pudemos dar um respaldo à escola e, nesse ano, a escola não fez nada, em geral, não é? (Excerto do depoimento de Supervisora de Ensino e Coordenadora de Avaliação da DE Beta, grifos meus)

É fundamental destacar uma das ponderaçôes da coordenadora do Saresp da DE Beta para que se pense a respeito das possibilidades de trabalho com base nos resultados. De acordo com seu posicionamento, que se ajusta à opiniáo desta pesquisadora, a Secretaria de Ensino parte de um pressuposto que não é correto, ou seja, as escolas, que normalmente se debatem com o problema da formação de professores, não têm um corpo docente especializado no entendimento de metodologias e técnicas de avaliação, mesmo porque este é um aspecto dificilmente trabalhado nos cursos de formação inicial. Como aponta Vianna:

Ainda que os resultados dos desempenhos sejam apresentados em escalas elaboradas por intermédio de rigorosos procedimentos estatísticos, e com a especificação dos vários níveis correspondentes de competência, dificilmente os professores têm condiçôes técnicas para interpretar dados que resultam da expertise técnica dos responsáveis pelos relatórios. (Vianna, 2003, p. 9)

Seria necessário um trabalho mais aprofundado e sistematizado de formação em avaliação, tanto dos educadores da instância intermediária (DE) quanto das escolas, para potencializar o entendimento do desenho da avaliação e dos seus resultados. A suposição que sustenta essa afirmação é a de que, ao compreender efetivamente os resultados, as equipes da diretoria e das escolas poderiam utilizá-los de maneira mais positiva, potencializando-os.

Finalmente, os depoimentos permitem observar que, além dos boletins de Orientação para a Interpretação dos Resultados, a sua divulgação se dá por três meios principais: o relatório de avaliaçáo (bastante complexo e detalhado, que demora cerca de dois anos para chegar às instituiçóes interessadas, tendo em vista seu caráter geral), os boletins das escolas (com uma análise dos resultados gerais e apresentaçáo de resultados quantitativos por turma e por aluno) e os dados quantitativos das diretorias.

Ainda que seja possível apontar um avanço na diferenciação desses relatórios, o fato de as diretorias e, mais especificamente, os grupos de supervisão e assistentes 
técnico-pedagógicos, alegarem que não recebem nenhum material para embasar suas reflexóes e seu trabalho, continua, do ponto de vista desta pesquisadora, chamando a atençáo, principalmente depois de tomar conhecimento da existência de um boletim de orientação para o trabalho. Fica a dúvida sobre porque o material não é citado na fala dos técnicos da diretoria entrevistados: os boletins não chegam às suas mãos? Há uma resistência em aceitar o material produzido pela FDE? Os materiais recebidos náo auxiliam no desenvolvimento do trabalho dos profissionais a que se destinam? Não se pode afirmar com certeza o porquê dos boletins de orientação não serem mencionados na entrevistas, fazendo com que surja a suposição de que este descaso se refere à própria avaliação. Tal fato mereceria ser investigado pela FDE, para que o trabalho realizado deixe de ser, aparentemente, inócuo.

Também parece um equívoco a diretoria não ter acesso aos dados gerais das escolas, uma vez que é a responsável mais direta pelo apoio ao trabalho a ser realizado com elas.

É possível concluir que as formas de divulgação de resultados mostram-se ineficientes, engessando ou, até mesmo, impedindo o trabalho a ser realizado nas diretorias. Os materiais de apoio mais mencionados durante as entrevistas foram os Relatórios de Avaliação, produzidos pela FDE/CENP. Mas esses materiais, por sua complexidade e nível de detalhamento, demoram a serem produzidos, e quando chegam à diretoria as equipes os consideram obsoletos, pois a avaliação tem mudado bastante a cada ano. São relatórios complexos, de leitura difícil, com questóes técnicas que, segundo alguns depoimentos, não são apreendidas pelos profissionais da diretoria, que acabam restringindo seu trabalho aos resultados enviados às escolas a cada ano.

$\mathrm{O}$ acesso a esses resultados não garante que se efetive um trabalho de apoio e formação do professor a partir dos mesmos, pois quando os resultados chegam, em meados do primeiro semestre letivo, fica mais difícil organizar dinâmicas de trabalho com as escolas. Talvez fosse interessante que esses resultados chegassem no início do ano, para que pudessem ser organizadas semanas de planejamento coletivas, quando especialistas trabalhassem com os professores os pontos a serem aprimorados. Esse desejo ecoa em diversos depoimentos dos técnicos da diretoria e na denúncia das próprias técnicas da FDE, que consideram que a prova anual prejudica o entendimento e o trabalho acerca dos dados, tendo em vista que não se garante, nem às escolas, nem aos órgáos, o tempo necessário para o estudo, o planejamento de ações e a concretização do trabalho a ser realizado a partir dos resultados. 


\section{REFERÊNCIAS BIBLIOGRÁFICAS}

AFONSO, Almerindo. Políticas educativas e avaliação educacional. Portugal: Universidade de Minho, 1998.

BITAR, Hélia et al. O Sistema de avaliação de rendimento escolar do Estado de São Paulo: implantação e continuidade. Idéias, n. 30, p. 09-20, 1998.

FREITAS, Luiz Carlos de (Org.). Avaliação: construindo o campo e a crítica. Florianópolis: Insular, 2002.

GARCIA, Carlos Marcelo. Formação de professores principiantes. In:

Formação e professores para uma mudança educativa. Porto: Porto Editora, 1999. p. 110130.

LAVILLE, Cristian; DIONNE, Jean. Em busca de informações. In: A Construção do saber: manual de metodologia de pesquisa em ciências humana. Porto Alegre: Artmed; UFMG, 1999. p. 168-197.

LUCKESI, Cipriano Carlos. Verificação ou avaliação: o que pratica a escola? Idéias, n. 8, p. 71-80, 1998.

MACHADO, Cristiane. Avaliação e política: limites e potencialidades. Tese (Doutorado) Universidade de São Paulo. São Paulo, 2003.
SÃO PAULO (Estado). FDE. Articulando a avaliação, gestão e formação no SARESP. São Paulo, 1998. [Fita de Vídeo]

SÃO PAULO (Estado). Secretaria da Educação. Documento de implantação do SARESP. [s.d.] . Comunicado SE/95. [s/d]. - Secretaria da Educação.

Orientações para a interpretação dos resultados. São Paulo: SEE; FDE, 2003. . SARESP: sistema de avaliação do rendimento escolar do Estado de São Paulo. São Paulo: FDE, 1997. . SARESP 98: manual de orientação.

São Paulo: FDE, 1998.

SOUSA, Sandra M. Zákia L. Avaliação da aprendizagem: natureza e contribuições da pesquisa no Brasil no período 1980 a 1990. Tese (Doutorado) Universidade de São Paulo. São Paulo, 1994. - Avaliação da aprendizagem: teoria, legislação e prática no cotidiano de escolas de $1^{\circ}$ Grau. Idéias, n. 8, p. 106-114, 1998.

VIANNA, Heraldo. Avaliações nacionais em larga escala: análises e propostas. São Paulo: FCC, 2003.

Recebido em: outubro 2008

Aprovado para publicação em: novembro 2008 